\title{
Tourism strategies for the renovation of mature coastal tourist destinations in Spain
}

\author{
F. Vera-Rebollo \& I. Rodríguez-Sánchez \\ Institute for Tourism Research, University of Alicante, Spain
}

\begin{abstract}
Tourism geography has studied the evolution pattern of tourism areas on a regional and local level through theoretical models and empirical analyses, which have been widely discussed. These research issues are still valid regarding the new trends in the tourist markets that have created a new scenario that makes it necessary to reopen the debate around the sun and sand tourism model. The mature coastal destinations with an economy that is fully dependent on tourism, or on the tourism-real estate relationship, face difficulties adapting to the tourism scenario created by the new demand trends linked to the cultural change in the era of post-modernism and the evolution towards a post-Fordist model. In this context, some theoretical models, such as Butler's tourist area life cycle theory, present mature tourist destinations in the Mediterranean as doomed to an irreversible decline. The significance of the changes, as well as their effects on the tourist areas, justifies a research project that is being developed to give an answer to some controversial questions: how can the decline of a tourist destination be defined and how can we measure it? How do we distinguish a critical crisis from a structural decline? How valid is the Tourism Area Life Cycle model as a theory to describe and predict future situations? What role do tourism planning and management play to avoid the decline of a tourist destination? What are the most convenient strategies and the most appropriate planning and management tools that can be used to renovate tourist destinations?

The present paper precisely seeks to answer the last question, analysing the recent tourism policies developed in Spain on a national, regional and local level and focusing on the renovation of mature coastal destinations. It is with this aim that policies, programmes and current actions are explored not only within a context characterised by the maturity of many destinations in their life cycle, but also in a scenario of global economic crisis.
\end{abstract}


Keywords: sun and sand tourism model, renovation, mature coastal destinations, tourism planning and management, resort life cycle.

\section{The renovation of mature coastal destinations within the framework of the tourism area life cycle theory}

The transformations that have occurred in the tourism market along with the actual life cycle of tourist destinations and the resulting obligation for the demand-receiving areas to adapt to the new global and regional dynamics justify the need to discuss and suggest ways to work for the renovation of the consolidated coastal tourist destinations located along Spain's Mediterranean coast [1].

Firstly, from a theoretical and analytical perspective, this new phase that numerous Spanish destinations are going through after more than forty years of mass tourism growth must be interpreted within the framework of the theories about the evolution of tourist destinations. From the theory point of view, the initial contribution made by Butler [2] has been followed by others, which revise and widen the scope of analysis [3,4] and are a sample of the interest and controversy that it still raises, the initial proposal having been enriched and its limitations highlighted with theoretical contributions and more recent case studies.

Secondly, from an applied and propositional perspective, the aim is to analyse the renovation strategies and actions undertaken in Spanish destinations because the large destinations associated with sun and beach tourism in a maturity phase constitute essential pieces in the international tourism framework which is under constant and complex reshaping. The contribution made by these destinations to the receiving tourism in Spain [5] is still essential (over 70\% of Spanish tourism) and so are its effects on the local and regional context, though we should not forget the tensions derived on a territorial and environmental level, as well as the same uncertainty about their future, all of which makes them become a research object of undeniable interest.

The analysis of this reality cannot be confined to an exclusively touristsectorial dimension, as the most operational ways of work must be faced from a global perspective in accordance with the paradigm of sustainability. That is how the strategies for the renovation and restructuring of destinations tend to link competitiveness and sustainability [6], in addition to granting special importance to the perspective of social agents, both from the point of view of perception about the destination and regarding the identification of the needs and priorities for renovation. This is an approach which connects with the concept of governance, where all the agents must have benefits and responsibilities, and tries to promote the application of local innovative and participative planning and management instruments.

One can thus make out a new scenario since consolidated coastal destinations face difficulties to adapt to the tourism scenario defined by the new demand trends associated with the cultural change of postmodernism, which have their replica in the supply's theoretical evolution towards post-Fordism $[7,8]$. 
In this context, some theoretical approaches, such as the tourist area life cycle theory, defend a certain determinism which supposedly confirms the unavoidable decline of mature Mediterranean destinations [9]. Thus, taking as a starting point the life cycle theory, Knowles and Curtis [10] put forward the thesis of the irreversible decline of Spanish second-generation sun and beach tourism destinations, those which began to develop during the 1960s and now have become mature destinations. In turn, Aguiló et al. [11] defend the survival of the sun and beach model and the efficiency of the renovation actions developed in such significant destinations as the Balearic Islands, as is demonstrated by the evolution in the arrivals of tourists and the satisfaction levels among the demand.

New analytical and propositional frameworks adapted to the situation and specificity of Spanish consolidated destinations can make it easier to know the evolution of tourist areas through the provision of theoretical models and empirical analyses both regionally and locally. As is pointed out by Agarwal [12], the signs of decline are the consequences but what matters most is to know its causes.

The perspective of analysis on which work has been carried out exceeds merely descriptive approaches to become a support tool for planning that can additionally be applied on consolidated coastal destinations seeking to encourage intervention strategies and instruments within the process of tourist area renovation on a territorial and environmental level. Nevertheless, the preliminary analysis about the reality of destination spaces reveals that the real estatetourism-based logic still prevails in their development, whereas the actions undertaken both from the public and from the private sector only respond partially to the reshaping process that is currently taking place in the tourism scenario and to the emergence of new destination-market relationships (Yeoman [13]). It can equally be perceived that the analytical instruments used to plan and manage tourism development show evident limitations to encourage and favour a better medium-long-term destination-market and, above all, to guarantee sustainable tourism development.

In short, it is necessary to perform a critical review of the different models and evolutionary theories about the tourist space, and particularly of Butler's tourist area life cycle theory. The aim is essentially to combine the basic tourism magnitudes (supply and demand) with the changes in the territorial and socioeconomic structure, an integrated analysis insufficiently developed in evolutionary models with a sectorial bias and, generally, with the number of tourists as the only explanatory variable. It becomes especially relevant to deal with the so-called 'stagnation' and 'decline' phases, the name and meaning of which are conceptually rethought by means of a different nomenclature: 'recessive' and 'structural crisis' situations.

The concept of tourist area life cycle shows parallelisms with the productive restructuring theories. Both approaches agree on the need to introduce correcting measures to avoid the effects of decline. In fact, within the framework of the productive restructuring theory, Agarwal [12, 14] regards the decline of destinations as the result of an interaction between internal forces (which reduce the destination's competitiveness) and external ones (which intensify 
competition), a global-local interaction process in which he defends the importance of local conditions and actions when it comes to modify regional or global processes. In this way, as opposed to determinist approaches, the local planning scale is revalorised seeking to maintain tourism competitiveness.

\section{The Spanish tourism policy in matters related to the renovation of mature tourist destinations: plans and projects}

The restructuring and renovation of consolidated tourist destinations is a need widely recognised by public and private agents before the generalised impression of change and the perception of crisis in some tourist models and destinations which has materialised in a loss of social and business profitability that could have serious consequences both territorially and environmentally.

Although this need is a very current issue now, it has already been present during the last few years in the Spanish tourism policy, which has gradually adapted to the changes experienced on a national and international scale, while at the same time it oriented its strategy regarding tools for the planning and management of tourist activity. In this sense, the great action lines in tourism matters have evolved from competitiveness criteria (Plan Marco de Competitividad del Turismo Español [Master Competitiveness Plan for Spanish Tourism] FUTURES I and II [15] to others based on quality (Plan Integral de Calidad del Turismo Español, PICTE [Quality Overall Plan for Spanish Tourism] [15]) until we have now reached a new cycle in which the principles inspiring the policy are based on the consolidation of leadership, the differential positioning of the supply, sustainability and the incorporation of an innovation culture.

The Ministry of Industry, Tourism and Commerce approved in 2007 the Plan del Turismo Español Horizonte 2020 [Horizonte 2020 Spanish Tourism Plan] [16], which suggests reformulating the development schemes of destinations in accordance with the new market trends and the challenge of sustainable development. This Plan recognises that the sun and beach product still represents the pillar of Spanish tourism but also highlights the need to improve and strengthen the competitiveness of the offer associated with it, which means working on the qualification of the tourist destinations referred to as 'mature' in the plan. The diagnosis offered by this Plan focuses on the environmental deterioration of a high number of destinations caused not only by an excessive and disorganised urban growth but also by the 'old age' of part of their hotel sector, especially in the sun and beach segment. The document also explicitly acknowledges the gradual reduction in profitability of the sun and beach product, which accounts for $75 \%$ of the receiving demand.

In response to this diagnosis, the Plan foresees a specific programme oriented to the requalification of mature tourist destinations with three broad action lines as follows. 


\subsection{Extraordinary projects for the requalification of mature destinations}

This is a programme which has as its aim to give technical and financial support to the development of extraordinary restructuring or overall transformation projects for a mature tourist destination with an international projection, developed and co-financed by the competent administrations and the business sector for the purpose of implementing a tourism model for the future. Three extraordinary projects exist within the framework of this programme that are currently being developed as pilot tests in three mature sun and beach destinations: Playa de Palma [Palma Beach] (Majorca, Balearic Islands), Costa del Sol Occidental [Western Costa del Sol] (Andalusia) and San Bartolomé de Tirajana (Gran Canaria, Canary Islands).

It is one of the axes within the requalification scheme that has a greater demonstration effect. Despite the peculiarities that are present in each one of these projects, all three of them have adopted as a common strategy the revision of tourism models with a long-term vision and an innovative as well as creative approach, the creation of Planes Directores [Master Plans] which can define the actions that need to be executed as well as the design of self-management and self-financing models which serve to guarantee the viability of the different projects. The most advanced one is the Plan de Reconversión [Restructuring Plan] for la Playa de Palma [17], as it was the first one to be set in motion. It proposes as the basic action lines: achieving an involvement of social agents for the success of the project, capturing the attention of investors who can bet on the destination, and succeeding in changing its image which is defined by disorganised urban growth and the lacks in infrastructures and services. Although the most immediate actions are going to focus on town planning and development interventions (mending damaged pavements and roads, corrective improvement of urbanisation in specific streets or more global areas, improvement of public lighting and public spaces) or in the improvement of the hotel offer, the medium-long term objectives include the overall restructuring of urban areas and the improvement of both drainage and water supply systems in various places.

For its part, Costa del Sol's Plan Qualifica [18], which affects 8 municipalities in the province of Málaga, foresees the design of strategic lines for the requalification of the tourism sector with the aim of increasing the destination's competitiveness level in the future with respect to other competitors taking as a starting point a number of strategies based on the revitalisation of tourist centres and spaces, the environmental quality of destinations, the modernisation of firms and the diversification and differentiation of products or the enhancement of public services and infrastructures, amongst others.

The degree of success obtained in these three projects will largely depend on the level of implementation of each Plan, which in turn is going to be determined by the budget proportion allocated to its execution taking into account the ambitious and costly objectives foreseen in the medium and long term. With that aim in mind, an effort has been made to create urban development Consortia supported on the financial contribution of the central and the corresponding regional administrations, as well as that made by private institutions. 
Apart from these three pilot destinations, there are many coastal resorts which find themselves in advanced maturity stages and which would require such farreaching renovation processes that they could even entail the adoption of a new tourism model. An Impulse Plan has been elaborated to achieve this aim. The Plan seeks to improve the access to funding for all types of mature destinations that wish to develop projects within the framework of a global restructuring or overall modernisation plan and that are implemented with the active participation of the different public administrations and the private sector. The Fund foresees a system of loans (which grant up to a maximum of 25 million $€$ ) with a long repayment term and at a low interest rate assumed by the Fondo Financiero del Estado para la Modernización de las Infraestructuras Turísticas [National (State) Fund for the Modernisation of Tourism Infrastructures] [19].

\subsection{Rehabilitation of urban and natural infrastructures and environments}

This is a general programme which seeks to support special action plans for the refurbishment or rehabilitation of tourism facilities or the urban and natural environments of destinations, improving the competitiveness-sustainability of the destination and paying special attention to the investments that have as their aim to recover environment and landscape quality as well as the 'sponging' of tourist areas.

\subsection{Modernisation of the tourism supply}

From a programme for the improvement or rehabilitation of tourism firms, one can encourage them to adopt the principles of specialisation and differentiation and make it easier for them to adapt to the demand requirements. This programme has materialised in the Plan Renove Turismo [19] promoted since 2009 by the Ministry of Industry, Tourism and Commerce in collaboration with the Instituto de Crédito Oficial [Official Credit Institute] [20]. The programme was based on a financing line with highly advantageous conditions such as a low interest rate, the coverage for a large proportion of the investment to be made (up to $90 \%$ ) and an extended repayment period for the funds granted (up to 12 years). For all these reasons, it was welcomed among the business sector, though the economic allocation for the programme (400 million $€$ ) was quickly exhausted and there were actually many businessmen who could not benefit from it. More precisely, the projects that received a boost were improvements or refurbishments, improvements with an effect on the accessibility, the sustainability or safety of establishments, the implementation of quality management systems and the creation or improvement of complementary infrastructures or amenities (garden, sports facilities, business centres, conventions, conferences, meeting rooms, car parks, etc.).

During that same year, the financing programmes were extended by means of a new plan, the Plan FuturE [19], which is still in force during the year 2010 for investments in the tourism sector that entail improved energy efficiency in tourism facilities, energy and water saving or the implementation of new quality technologies and systems, amongst other aspects. This is a financial aid 
programme that specifies more accurately the concepts for which funding is granted and that is consequently less often demanded by the business sector.

Therefore, the start of overall requalification programmes of great magnitude along with the provision of advantageous financing lines to the business sector and to the tourist destinations have been the response given by the central government -through its tourism policy- to the present conditions of growing competitiveness that make necessary the restructuring of mature destinations.

\section{Renovation and action programmes in the regional context}

In addition to the initiatives developed within the framework of the extraordinary requalification plans for mature destinations, some Spanish regions situated along the Mediterranean coastline which have based their tourism development on the sun and beach model have devised planning instruments meant to orient the renovation initiatives undertaken in this type of destinations. We find a good example in the Plan General de Turismo Sostenible de Andalucia [General Plan for Sustainable Tourism in Andalusia] (2008-2011) [21], where an important reflection is made on the unmistakable signs of maturity which are visible not only in the Andalusian business sector but also in some tourist destinations, within a context where the European market itself starts to show signs of saturation. The Plan advocates a policy based on differentiation, quality, innovation and sustainability and puts forward as an instrument for the execution of the Plan the creation of a Plan Director del Ámbito Litoral [Master Plan for Coastal Areas] that will incorporate measures to reduce the processes of tourist appeal loss and to modernise the sun and beach segment, amongst others.

It is worth mentioning some recent innovative initiatives on the same regional scale, such as the one implemented by the government of the Balearic Islands that approved in 2009 a regulation to stimulate investment on the archipelago, with a special focus on the need to modernise hotel establishments as one of the basic pillars of renovation. To that end, the regulation offers the possibility to increase the hotels' building surface area by up to $10 \%$ if these establishments undertake refurbishments or improvements oriented to raise their official category. This Plan for the ongoing modernisation of the hotel sector also contemplates the opening of specific information offices that will simplify the administrative authorisation procedures as well as the access to national financial aid lines for the rehabilitation and improvement of tourism establishments.

In the specific case of the Valencian Region, renovation has also been undertaken from the Plan de Competitividad del Sector Turístico de la Comunidad Valenciana [Competitiveness Plan for the Tourism Sector in the Valencian Region] (2009-2011), which seeks to provide an impulse for the Valencian tourism economy [22]. One of the priority axes is precisely that of the modernisation and adaptation of the business fabric as an essential part in the renovation of destinations. A set of schemes or incentives have been created for this purpose to finance projects entailing a qualitative improvement of tourist destination and firms from different action perspectives. The most significant subsidy programmes are focused on business firms, on the local institutions, and 
on the business associations within the tourism sector. More precisely, the aids for firms belonging to the tourism sector revolve around three great areas: aids for the existing supply (demand segmentation, environmental and technological improvement, diversification, service excellence and commercialisation), creation of a non-conventional tourist supply and implementation of (quality, environment, and accessibility) management systems. The planning instruments on a regional level consequently bet on renovation too and there are initiatives for the modernisation of key sectors such as hotels or incentive lines meant to improve the competitiveness levels of both firms and destinations.

\section{Relevant actions in the local context: Benidorm as an example of a mature tourist destination}

Within this global context, it becomes particularly interesting to analyse the intervention strategies on a local scale in the case of a coastal tourist destination like Benidorm. With a tradition of more than 40 years in the delivery of tourism services, Benidorm exemplifies the situation of those centres which arose in the 1960s following the boom of mass tourism in Spain.

Despite being a tourist destination which has had a positive balance in its tourist activity so far (high percentage of international demand, considerable volume of formal regulated offer, high levels of hotel occupancy all year round, low seasonality, high average length-of-stay of tourists), the new demand trends along with the evolution of the market make it advisable to adopt new action lines. More specifically, there are some objective aspects which suggest the necessary restructuring of its tourism system: the excessive dependence on the British market (which has been seriously affected by the devaluation of the pound and by the widespread economic crisis), the changes in the traditional travelling model of tourists (more independent travellers and tour operators that divert their demand towards new more profitable destinations), reduced business profit margins and a deterioration of the destination's brand image with the resulting negative connotations for some demand segments.

Local governments have progressively introduced new tourist attractions with a clear goal: the diversification of the destination (theme and leisure parks, amongst others), and efforts have been made to capture new demand segments (conferences and conventions) as well as isolated urban requalification interventions (construction of the new Poniente promenade) although there are no planning instruments available that can help orient the renovation of the leisure city as a whole. Nevertheless, the reinforcement of the destination's image before the existing and potential markets has been a constant element on this destination's goals, which is why a business group or Federation has been created to implement joint promotion and, simultaneously, work is being carried out to develop a new local management model, a public-private body (under the legal formula of a foundation): Turisme de Benidorm, a body which responds to the evident need for businessmen in this sector to take an active part and feel represented in the promotional management of the destination. This action is in 
tune with the bet that many towns have made on new management formulas based on the creation of mixed bodies including the participation of the Local Administration -together with that of the business sector- in the tourist management and promotion of destinations. In recent years, these initiatives have counted on the support of the Secretaria General de Turismo [General Secretariat for Tourism] and the Federación Española de Municipios y Provincias [Spanish Federation of Municipalities and Provinces] [23] (a nationwide association of local and provincial bodies) from a joint set of incentives meant to facilitate the creation of this type of institutions or the reinforcement and transformation of the already existing ones with a funding shared by the Town Councils and the Federation (45\% each) and the private sector $(10 \%)$. This body is inspired in the successful public-private management model of Turisme de Barcelona, a consortium created in 1993 as a joint initiative of three major institutions: the Town Council, the Chamber of Commerce and the Barcelona Promoció Foundation. In the specific case of Turisme de Benidorm, the institutions involved will be the Secretaria de Estado de Turismo [State/National Secretariat for Tourism] and the Town Council - both of which will assume $90 \%$ of the financing of this body on equal parts - along with the Asociación Empresarial Hostelera de Benidorm y de la Costa Blanca [Hospitality Business Association of Benidorm and the Costa Blanca (the most representative business association in the destination) that will provide the remaining $10 \%$.

Many of the recent actions have been favoured by the existence of the Fondo Estatal para el Empleo y la Sostenibilidad Local [State/National Fund for Employment and Local Sustainability], one of the fundamental axes in the Plan Español para el estímulo de la Economía y el Empleo [Spanish Plan for the stimulus to the Economy and Employment] [24]. That Fund has been created in a context characterised by a situation of recession to finance the undertaking by the local authorities of employment-generating investments and actions which can contribute to economic, social and environmental sustainability, among which stand out those directly or indirectly related to tourist activity. In the specific case of Benidorm, the whole investment coming from this financing source during 2009 has been oriented to interventions connected with urban renovation and the improvement of the urban scene and mobility.

As for the business sector, and especially the hotel sector, there is proof of the enormous effort made in the renovation of the establishments and also of some initiatives for the introduction of new business models as an element of diversification for the destination. In this respect, the new establishments built incorporate additional offers to sun and beach and try to orient themselves towards demand segments with a higher purchasing power (spas and wellness and beauty centres, select restaurants, events, conferences and conventions, etc.). Regarding the renovation of hotel establishments, we have been able to verify that practically half of the offer was built between the 1960s and the 1970s and also that the refurbishments of hotel establishments as a maintenance task have been constant, to which must be added that about $90 \%$ of them have gone 
through improvements of a greater magnitude since the 1990s and until the present day in order to progressively adapt to the new quality demands dictated by the market. Although it is difficult to make a typology of the investments made in renovation by Benidorm's hotel sector, as is pointed out by Vera et al. [25], the purpose in a large part of the renovations has been to modernise the premises, to acquire new equipment, the removal of architectural barriers and the construction of new complementary facilities (car park areas, spas, gyms...). Most of the hotels analysed have included among their renovation objectives the enlargement of their capacity, or its reduction, in order to create spaces with new dimensions, to address segments with a higher purchasing power, to reorient their business completely or to differentiate themselves with the aim of obtaining a competitive advantage over similar establishments. A significant part of this renovation or modernisation of establishments has been supported with aid programmes from public administrations, especially the regional administration, through a series of grants or subsidies offered every year to promote the implementation of management systems, projects connected with the new technologies, adaptation to disabled people, etc., the most relevant incentive because of its direct impact on the qualification and renovation of the supplybeing the one which supports the rise in the official category of establishments (according to figures provided by the Conselleria de Turisme [Regional Government Tourism Department], a total of 33 establishments increased their category in Benidorm during the period comprised between 1998 and 2009). In addition to this economic support, the business sector has benefited from some isolated actions undertaken by the local administration such as the modification of the Plan General de Ordenación Urbana [General Urban Organisation Plan] which was carried out in 2001 with the aim of favouring the renovation of the hotel offer and creating four- and five-star complexes through the transformation of two- and three-star ones. A number of benefits were subsequently granted to certain tourism establishments after the implementation of this measure:

- a $40 \%$ increase in the building surface area for hotels with four or more stars, destined to reception rooms, indoor swimming-pools, squash and sauna.

- an increase in room size and the 'non-count' of lobbies, corridors, staircases, warehouses, lifts, technical premises, terraces and car parks in hotels with three or more stars.

The last and most recent initiative has been one based on the recycling of obsolete establishments to which an alternative use can be given as holiday apartments, offices or retail businesses. This initiative materialised in 2008 with a specific modification of the Plan General de Ordenación Urbana in the municipality and sought to permit a different use for old establishments located in the centre of Benidorm which were offered at very low prices due to the impossibility for them to adapt to the new demand needs because of their location and the lack of space for new facilities such as car parks, swimmingpools, etc. 


\section{Conclusions}

Faced with a context of crisis and deep global adjustments in the economy which affect tourism consumption patterns and the growing competition between visitor-receiving areas, the tourism policy in Spain has oriented part of its efforts to support and boost the restructuring of destinations focused on mass tourism and to improve the situation of their firms by means of action lines which materialise in investments meant to improve the infrastructures and urban scenes of tourism, and to achieve a renovation of their establishments.

Several pilot projects have been set in motion for this purpose as a demonstration example for tourist destinations, focused on renovation. Nevertheless, the business agents have generally described the actions of the administration in this field as 'not very significant'. In parallel, one can perceive an interest in encouraging advanced and more participative tourism management formulas based on public-private collaboration and cooperation before the need to join efforts and work on the basis of shared objectives. One of the pillars of this new model is reinforced through the cooperation between administrations, adapted to the principle of shared responsibility, both for the intervention on the different administrative levels and for the provision of the economic resources required through the signing of financing agreements with public and private contributions. However, it is necessary to make sure that mixed management initiatives and demonstration experiences do not become isolated actions. Instead, they should become increasingly widespread and usual formulas.

This type of issues arise during the study of the city of Benidorm, the paradigm of a mature international tourist destination in the Mediterranean area, which shows the boost given to cooperation between public and private agents, though the efforts have focused almost specifically on the tourism promotion side, which leaves aside the possibility to structure a wide range of action lines that can cover the variety of aspects which are linked to the renovation of the destination: issues associated with town-planning and urban image, environmental management, actions meant to improve the product and new infrastructures, amongst others. In the specific case of Benidorm, one can check the absence of an overall integrating strategy oriented to the renovation of the destination despite some public initiatives. The change processes perceived consequently derive from the effort made from the business sector to invest in the improvement of their establishments as a strategy for survival in an everchanging and increasingly competitive and demanding market as far as quality is concerned. Regarding the planning instruments oriented to the renovation of mature destinations, some normative and regulatory approaches have emerged both nationally and regionally. However, in the local context, each destination responds differently before the need for renovation and the strategies implemented vary to a large extent both in their formulation and in the results obtained. 


\section{Acknowledgements}

The present paper has been carried out within the framework of the research project Renovación de los destinos turísticos consolidados del litoral: nuevos instrumentos para la planificación y gestión (RENOVESTUR) [Renovation of coastal consolidated tourist destinations: new instruments for planning and management] of the Plan Nacional $I+D+I$ 2008-2011 [2008-2011 R\&D\&I National Plan] by the Ministry of Science and Innovation.

\section{References}

[1] Vera, J.F. \& Ivars, J.A. (2003): 'Measuring Sustainability in a Mass Tourist Destination: Pressures, Perceptions and Policy Responses in Torrevieja, Spain', Journal of Sustainable Tourism, 11, 2\&3, 181-203.

[2] Butler, R.W. (1980): "The concept of a tourist area cycle of evolution: implications for management of resources", The Canadian Geographer, XXIV, I, pp. 5-12.

[3] Butler, R.W. (2006a): The tourist area life cycle. Applications and Modifications, Vol. I, Clevedon, Channel View.

[4] Butler, R.W. (2006b): The tourist area life cycle. Conceptual and Theoretical Issues, Vol. II, Clevedon, Channel View.

[5] Instituto de Estudios Turísticos (2009) available in http://www.iet.tourspain.es

[6] Ritchie, J.R.B. \& Crouch, G.I. (2003): The competitive destination: A sustainability perspective, Wallingford, CABI Publishing.

[7] Urry, J. (1990): The Tourist Gaze: Leisure and Travel in Contemporary Societies, Londres, Sage.

[8] Ioannides, D. \& Debbage, K. (1998): "Neo-fordism and flexible specialization in the travel industry", in The economic Geography of the tourist industry, (Ioannides, D. \& Debagge, K., editors), Routledge, London, pp. 99-122.

[9] Bramwell, B. (2004): "Mass Tourism, Diversification and Sustainability Development in Southern Europe's Coastal Regions", in Bramwell, B. (ed.), Coastal Mass Tourism. Diversification and Sustainable Development in Southern Europe. Clevedon, Channel View Publications, 1-31.

[10] Knowles, T. \& Curtis, S. (1999): “The Market Viability of European Mass Tourist Destinations. A post-stagnation life cycle analysis", International Journal of Tourism Research, 1, pp.87-96.

[11] Aguiló, E., Alegre, J. \& Sard, M. (2005): “The persistence of the sun and sand tourism model", Tourism Management, 26, pp. 219-231.

[12] Agarwal, S. (2005): "Global-Local interactions in English Coastal Resorts", Tourism Geographies, 6, 4, 351-352.

[13] Yeoman, I. (2008): Tomorrow's tourist. Scenarios \& Trends. Amsterdam, Elsevier Science.

[14] Agarwal, S. (2002): "Restructuring seaside tourism. The resort lifecycle", Annals of Tourism Research, 29, pp. 5-55. 
[15] http://www.sgt.tourspain.es

[16] http://www.turismo2020.es

[17] http://consorcioplayadepalma.es

[18] http://www.qualifica.org

[19] http://www.mityc.es

[20] http://www.ico.es

[21] http://juntadeandalucia.es

[22] http://www.comunidad-valenciana.org/

[23] http://www.femp.es

[24] http://www.plane.gob.es/

[25] Vera, F., Rodríguez, I. \& Capdepón, M., Reestructuración y competitividad en destinos maduros de sol y playa: la renovación de la planta hotelera de Benidorm en XIII Congreso Internacional de Turismo, Universidad y Empresa, Universitat Jaume I, Castellón, 2010. 